\title{
EREBEA
}

Revista de Humanidades

y Ciencias Sociales

NúM. 5 (2015), pp. 243-272

ISSN: 0214-0691

\section{Las ÁREAS DE INCURABLES DEL Hospital de la SANGre de SeVilla}

\author{
Paula Ermila Rivasplata Varillas \\ Universidad de Sevilla
}

\section{RESUMEN}

El hospital de la Sangre de Sevilla fue creado para atender a mujeres con enfermedades comunes que no padecieran enfermedades contagiosas ni fuesen incurables. Sus diversos reglamentos -1503 , 1603, 1624, 1734- prohibieron el acceso de incurables al hospital; sin embargo, la realidad se impuso y los libros capitulares revelaron que este hospital recibió a mujeres y eclesiásticos incurables y de avanzada edad que esperaban un buen morir física y religiosa. Este hospital tenía asilos separados sexualmente en los que se acogían incurables y ancianos, por limosna o previo pago. Se debe remarcar que los incurables no eran agonizantes, sino personas que por diversos motivos no se valían de sí mismas y cuyas enfermedades sin ser contagiosas no tenían curación.

\section{Palabras Clave}

Incurables; ancianos; jubilados; Hospital de la Sangre de Sevilla; Antiguo régimen.

Fecha de recepción: 24 de enero de 2015

Fecha de aceptación: 30 de octubre de 2015

\section{Abstract}

The Blood Hospital of Seville was created to care for women with common diseases who did not suffer contagious or incurable ones. Its various regulations $-1503,1603,1624,1734-$ prohibited the admission of incurable women to the hospital, but reality set in and Hospital records show that it received both the elderly of the Church and women of advanced age. The hospital had asylums separated by sex, and the incurable and elderly were cared for, either through alms or payment. It is necessary to highlight that the incurable patients were not agonizing, but rather were persons who for diverse reasons could not care for themselves, and whose diseases, though not contagious, were incurable.

\section{KEYWORDS}

Incurable patients; the elderly; pensioners; the Blood Hospital of Seville; Ancient Regime. 

El Hospital de la Sangre de Sevilla fue fundada para atender mujeres no contagiosas ni incurables en 1500 y esto se remarcó en sus constituciones, sin embargo existieron dos áreas separadas que recibían a mujeres y hombres incurables. ${ }^{1}$ En un comienzo sólo eran admitidos los trabajadores religiosos y laicos de la propia institución que habían llegado a la senectud, proporcionándoles una cama, atención y manutención. Estas personas no eran cualquier trabajador sino sólo los que habían permanecido en el hospital por mucho tiempo, demostrando fidelidad a la institución. Sin embargo, también el hospital cobijó a cualquier eclesiástico que había envejecido pobre y sin un techo, así como a mujeres que entraron por caridad, recomendación o previo pago. ${ }^{2}$

Este trabajo fue realizado consultado las fuentes documentales del hospital de la Sangre que resguarda el archivo de la Diputación Provincial de Sevilla, especialmente los libros capitulares, inventarios, libros de ingresos y gastos, así como sus reglamentos. La información obtenida ha sido confrontada, obteniéndose interesantes resultados que indican que la realidad supera la reglamentación. Una realidad que no hubiera podido ser descubierta, sino se investigaba minuciosamente la documentación primaria de este hospital. ${ }^{3}$

1 Justiniano y Martínez, Manuel. Hospital de las Cinco Llagas (Central) de Sevilla. Sevilla: Imprenta Provincial, 1963. 2da edición, p. 8. El Papa Alejandro VI otorgó la Bula de Fundación el 13 de mayo de 1500. Carmona García, Juan Ignacio. "Cinco siglos de historia: trayectoria institucional y asistencial del hospital de la Sangre", en El edificio sede del Parlamento de Andalucia : el Hospital de las Cinco Llagas, Sevilla: Parlamento de Andalucía ; Oviedo : Nobel, 2007, pp. 81-105. Roda Peña, José, La virgen del Tránsito y el Hospital del Pozo Santo de Sevilla. Sevilla : Congregación de Religiosas Terciarias Franciscanas del Tránsito y Asunción de Nuestra Señora, 2004, p. 21. Había otros hospitales en Sevilla que atendían a incurables como el Pozo Santo que estaba en la colación de San Andrés, fundado en 1666 por las beatas terciarias franciscanas Marta de Jesús y Beatriz de la Concepción. Socorrer a pobres mujeres desamparadas, impedidas o incurables, asistiéndolas en su enfermedad y ayudándolas a bien morir.

2 Carmona García, Juan Ignacio. El extenso mundo de la pobreza: la otra cara de la Sevilla Imperial. Sevilla: Servicio de Publicaciones de la Universidad de Sevilla, 1993, pp. 19-32. Sobre la pobreza en Sevilla.

3 Barriga, Carmen et al. Hospitales y centros beneficos sevillanos: inventarios de sus fondos. Sevilla: Diputación Provincial de Sevilla, 1997, pp.15-62. 
I. Normas no cumplidas: Prohibición tacita de Recibir incurables Ni CONTAGIOSAS

Desde la fundación del hospital, se determinó que existiese un físico o cirujano que revisara a las enfermas antes que fuesen admitidas en el hospital con el fin de que sólo permitiese el ingreso de enfermas con enfermedades comunes. ${ }^{4}$ Según la norma, este hospital no recibía a enfermas portadoras de enfermedades contagiosas (mayormente de bubas o lepra), ni las que requerían curaciones complicadas e incurables, siendo derivadas al hospital que correspondiese su curación. ${ }^{5}$ No se recibían a incurables, ni contagiosas, ni héticas, tísicas, gálicas, sarnosas, tiñosas, ni embarazadas para parir. ${ }^{6}$ Esto se hacía porque en Sevilla existían otros hospitales especializados en lepra, bubas con el fin de evitar perjuicios a las demás enfermas o a la "gente que las asistían". " Si la enfermedad era dudosa, el administrador tomaba la última decisión y podía inclinarse a favor de la enferma hasta que se determinaba su enfermedad. Sin embargo, se encuentran ingresos de enfermas no permitidas según constitución, portadoras de "males contagiosos", incurables, embarazadas y esclavas cautivas, cuya entrada de tiempo en tiempo era reiteradamente prohibida como en 1675 y en $1678 .^{8}$

De esta manera, la realidad se impuso y fueron admitidas en diversas circunstancias personas no permitidas. ${ }^{9}$ Por ejemplo, al desatarse alguna epidemia,

4 ADPS (Archivo de la Diputación Provincial de Sevilla) Legajo 1A. Constitución de las Cinco Llagas de 1503.

5Domínguez-Rodiño y Domínguez Adame, Eloy. "El Hospital de las Cinco Llagas", en Hospitales de Sevilla. Utrera: Real Academia Sevillana de Buenas Letras. Grafitres S. L.,1989, pp. 103-104. A pesar de estar destinado a enfermos no contagiosos, a veces en épocas de peste se les admitieron, como en 1580, 1649, 1709

6 ADPS. Legajo 4B. Libro de autos capitulares pertenecientes al gobierno de este Hospital de la Sangre de 1734 a 1763, f.108 v (1751).

7 B.C. (Biblioteca Colombina) Constitución del Hospital de las Cinco Llagas de 1734. Fondo Gestoso V. Const.o 9. Acuerdo del año 1675, f.135 r. Zaragoza Rubira, Juan Ramón, "La evolución histórica de la asistencia hospitalaria", en Hospitales de Sevilla, Utrera, Real Academia Sevillana de Buenas Letras, Grafitres S. L.,1989, pp. 130-131.

8 ADPS. Legajo 4B. Libro de juntas o actas capitulares de patronos del Hospital de las Cinco Llagas de 1659 a 1687, f.135 r (1675): “...atento a que tienen noticia que se reciben en este hospital algunas enfermas de males contagiosos y otras incurables y que asimismo se traen a curar al dicho hospital algunas esclavas cautivas de aquí adelante no se reciba ninguna de las tres especies, (sin licencia especial de los patronos reverendos(tachado))sobre que encargan la conciencia al Sr. administrador y a los demás ministros para que den cuenta de lo que se hiciere y quien ocasionó la dicha entrada y recibo". ADPS. Ibidem, f.150 r (1678): “... se tiene noticia que por diferentes favores se suelen recibir para curación en este hospital algunas esclavas con diferentes pretextos, acordaron y mandaron que el Sr. Administrador no reciba a ninguna esclava para curación"

9 López Falante, Dolores y Paz de la Torre Liébana, María de la. "El Hospital de las Cinco Llagas de Sevilla: un modelo de organización de instituciones de beneficencia durante el Antiguo Régimen”, en Archivo Hispalense. Sevilla: Tomo LXXVIII. No 237,1995, pp. 61. Las ordenanzas detallan los deberes del personal femenino y masculino del hospital y reconocen usos y costumbres 
este hospital habilitaba habitaciones para recibir a los infectados, generalmente a pedido de las autoridades civiles de la ciudad, que asumía los gastos. La experiencia enseño que las personas que atendían a los enfermos podían caer enfermos incluso de enfermedades contagiosas, en estos casos, el médico tenían la obligación de curar a todos los criados del hospital de cualquier enfermedad que tuviesen, aunque fuese contagiosa, según el libro de acta capitular de $1604 .{ }^{10}$

\section{LOS CLÉRIgOS INCURABLES DEL HOSPITAL}

A pesar de la tacita prohibición de recibir incurables indicada en los reglamentos, este hospital se vio obligado a hacerlo para cobijar a sus propios religiosos e incluso a veces a algunos curas pobres que acogían del exterior. Así al trasladarse el hospital a su nuevo establecimiento en el arrabal de la Macarena en el espacioso edificio renacentista se habilitó un área para cobijar a los religiosos incurables que no tuviesen otro lugar donde alojarse desde $1567 .{ }^{11}$

En la enfermería de incurables eclesiásticos estaban los curas de menor jerarquía del hospital, pues el administrador recibía una casa de las muchas que tenía el hospital, además de un estipendio mensual y el mayordomo, una habitación independiente en el hospital, con algún salario anual. Los curas que atendían a las enfermas, al envejecer, se les jubilaba y cesaba el pago del salario, pero mantenían su ración de comida diaria, asistencia sanitaria y espiritual y recibían una cama de incurables en enfermería de eclesiásticos. Algunos curas al alcanzar la senectud, seguían trabajando, recibiendo su salario, pero estaban exentos de realizar misas. En épocas económicamente difíciles para el hospital, el cura que lo reemplazaba, trabajaba sin recibir salario por su trabajo porque era entregado integro al jubilado; sin embargo, el nuevo cura recibía el dinero correspondiente a las misas realizadas. Al fallecer el cura jubilado, entonces el que lo había reemplazado empezaba a recibir su salario completo. No faltaba trabajo para los curas en el hospital donde se les pagaba por cada misa de difuntos, entierros y capellanías.

que ya se llevaban a cabo en la práctica.

10 ADPS. Legajo 4A. Autos capitulares de 1584 a 1635, f.49 r.(1604).

11 Justiniano y Martínez, Manuel, Op. cit., p. 19. A fines de 1558, los patronos del hospital, los priores del convento de Santa María de las Cuevas, San Jerónimo de Buenavista, San Isidoro del Campo, acordaron que se usara un cuarto grande que caía a poniente del nuevo edificio, trasladando el Santísimo Sacramento, las enfermas y lo demás, el domingo 5 de marzo de 1559. Carmona García, Juan Ignacio, "Cinco siglos de historia..., Op.cit, p.85. Según el inventario del 1 de septiembre de 1567 había una enfermería de eclesiásticos con 22 camas. Jiménez Martin, Alfonso. "Fechasde un lugar. Cronologia documentada del contexto, antecedentes, construcción y uso del hospital de las Cinco Llagas o de la Sangre, sede del Parlamento de Andalucía”, en El edificio sede del Parlamento de Andalucía: el Hospital de las Cinco Llagas. Sevilla: Parlamento de Andalucía ; Oviedo : Nobel, 2007, pp. 215-247. 
Según la norma, en esta enfermería eran recibidos clérigos de cualquier orden que fuesen profesos, de todas las enfermedades que no fuesen contagiosas ni incurables. Sin embargo, esta enfermería se convirtió en un asilo de eclesiásticos ancianos e incurables. A su cuidado estaba un enfermero que cuidaba que fuesen servidos con el respeto que a tales personas se debía y con mucho regalo sin excusar gasto ni trabajo.

El enfermero de estos ancianos incurables se encargaba de limpiar la habitación, entregarles la comida, recoger los trastos, recoger la ropa sucia y renovarla, limpiar los orinales y atenderlos en lo que solicitaran. ${ }^{12}$ El enfermero se acercaba a horas puntuales en los momentos establecidos y requeridos. Se trataba de no perturbar a los curas en sus meditaciones con presencia extraña, por eso el enfermero de eclesiásticos no se dedicaba exclusivamente a esta tarea era, también, ayudante de botica o sacristán, cumpliendo con las dos ocupaciones. Incluso el enfermero de eclesiásticos dormía en un cuarto colindante y separado a la sala de eclesiásticos junto con los enfermos laicos del hospital (portero, tahonero....).

La primera vez que se menciona a este enfermero de eclesiásticos incurables fue en 1567, siendo la constitución de 1603 que formalizó este cargo. ${ }^{13}$ En la constitución de 1624, se requería que el enfermero estuviese presente durante las visitas del médico y cirujano. ${ }^{14}$ Sus actividades se ampliaron, incluía hacer las unciones y avisar al cura semanero para la extremaunción. En el siglo XVII, esta enfermería de uso exclusivo para los religiosos del hospital, se amplió para sus trabajadores laicos, pero en habitación aparte. A veces se acogía a religiosos externos. ${ }^{15}$

Treinta y dos enfermeros para eclesiásticos incurables hubo en este hospital en el siglo XVII. Entre los cuales destacó un enfermero de eclesiásticos y ayudante de botica llamado Bartolomé Marín que trabajó dieciséis años (1667 a 1683) y logró

12 ADPS. Legajo 1B. Autos capitulares de 1556 a 1584, f.27 v.(1568).

13 ADPS. Legajo 1 A. Constitución de 1603.

14 ADPS. Legajo 1A. Constitución de 1624.Los patronos visitaban, con la asistencia del médico, a cada una en las salas de enfermas de medicina, y con el cirujano mayor en las de cirugía, pasando después a las impedidas o incurables y enfermerías de convalecencia de mujeres y de hombres. Preguntando a las mismas enfermas sobre su asistencia, aseo, curación, raciones y regalos, se enteraban del cuidado que dispensaban las enfermeras.

15 Morales Padrón, Francisco, et al. Los Venerables. Sevilla: Fundación Fondo de Cultura de Sevilla, 1991, p. 12: Después de la peste de 1649, la situación precaria de sacerdotes ancianos, desvalidos y enfermos o transeúntes que no contaban con un local donde acogerse, empeoró. El número de clérigos entonces existentes era muy superior a las necesidades de la población. La antigua hermandad del silencio, es decir, la hermandad de Jesús nazareno, situada en el hospital del Señor San Antón en 1627, acogía a sacerdotes olvidados. La hermandad del San Bernardo decidió asumir la casa hospicio amparo de Venerables Sacerdotes. Ramos Carrillo, Antonio. La sanidad sevillana en el siglo XIX: el hospital de las Cinco Llagas. Sevilla : Diputación De Sevilla, 2004, p.31. El hospital de Nuestra Señora de la Paz o de San Juan de Dios para pobres incurables no fue reducido en 1586 y se mantuvo vigente. 
jubilarse, pero por ser un criado no se le podía designar una cama de incurables. Entones, se le dio un trabajo mucho más tranquilo como fue el cuidado del reloj del hospital, designándole un salario para tal función, además de una ración de comida y vino. Sin embargo, continuó siendo enfermero de eclesiásticos y relojero hasta 1693, trabajando por diez años más con la ayuda de otro enfermero, Felipe del Camino, cuando falleció. ${ }^{16}$

El área de enfermería de eclesiásticos incurables recibía a veces atención médica, se primaba la espiritual, pero a partir del siglo XVIII, no sólo el médico sino también el cirujano empezaron a ser obligados a visitar esta enfermería más asiduamente, en el que estaban presentes el enfermero de los ministros, el boticario y la enfermera mayor. ${ }^{17}$ En el mencionado siglo, el enfermero de eclesiásticos podía ser el sacristán mayor y asistir a los enfermos en todas sus enfermedades. Sin embargo, esta área de incurables se cerró temporalmente por falta de renta en 1716 y ya no se tiene noticia que se volviese a abrir.

\subsection{Descripción de la enfermería de clérigos del Hospital de la Sangre}

El primer inventario que lo menciona es el de 1567 que fue el año de su creación. Se trataba de una habitación larga y muy bien equipada con muchos cuadros religiosos. Aparador grande, un banco para repartir la comida, una tablilla de cortar carne, una tablilla o mesa donde se ponían los platos para comer, cuatro bancos de tabla para sentarse a la mesa, veinte mesitas redondas en que comer los que no se podían levantar, veinte manteles para las mesitas de los enfermos, seis servidores con sus paños, dos calderetas para agua y para lavar platos, un salero de estaño, una alcuza de cobre, veinticinco platos de estaño, veinticuatro escudillas de estaño, veinticuatro jarros de estaño, un jarro de pico para lavar las manos, unos pares de manteles grandes de camas de a cuatro varas para la mesa de los enfermos. También, seis vasillos de hoja de Milán para los ungüentos, unas toalla para el barbero, cuatro candeleros de palo para poner candiles, cuatro candiles con sus candilejas, una bacinera de palo para poner las bacinicas y las jeringas, doce bacinicas de azófar para escupir, tres jeringas, un brasero de hierro, un tintero de plomo, dos cuchillos y veintidós camas con sus implementos.

En el inventario de 1603 y 1613 había once camas, un altar que tenía un frontal con el escudo de las Cinco Llagas con sus manteles y un retablo del nacimiento y un cristo de bulto, dos candelabros de azófar, un anafe de hierro, dos candelabros de madera y sus candiles y una banca con su lienzo que servía de cortador de raciones de comida. En 1636 había ocho camas en la sala de

16 ADPS. Libros de recibo y gasto. Legajos 111 a 124.

17 ADPS. Legajo 4C. Libro de Auto Capitulares del Hospital de la Sangre de 1788 a 1800, f.26 r (1791). 
los enfermos eclesiásticos, que estaba separado del enfermero y el criado que los atendían. Camas de bancos y tablas de bronce con dos colchones, dos sábanas, dos almohadas, dos cobertores, uno de pelo y otro de paño. En una sala de afuera había tres camas, una para el enfermero y dos para algunos criados de casa que se curaban en ellas. Cada una con bancos y tablas, dos colchones, dos sábanas, dos almohadas, dos cobertores, uno de pelo y otro de paño.

En 1685 figuraban en el cuarto de eclesiásticos: un cuadro grande del nacimiento en su marco, un cuadro de las Cinco Llagas muy viejo, un cristo de madera en su cruz con una peana antigua, un pequeño cuadro de Nuestra Seńora del Rosario, cuadros de Magdalena, San Cayetano, Santísimo Sacramento y Nuestra Seńora del Pópulo. También, dos cajones de pino, un banco grande, una mesilla pequeña de pino, siete banquillos de pino, veintisiete bancos de cama de borde con sus pies de hierro y cuarenta tablas de borde para armar diez camas, dos cacillos de mano para calentar aceites, un velador con dos candiles de garabato, dos lebrillos vidriados para sangrar, tres tarimas, ventosas, orinales, un candil, una silla grande, dos bufetillos pequeños, un arca de nogal, tres sillas de paja y una cama del enfermero.

La enfermería de incurables de eclesiásticos simulaba un lugar de descanso con sillas de diversos tipos, con pocas camas, decorada con cuadros grandes de pintores de renombre de la talla de Murillo y Zurbarán. ${ }^{18}$ En resumen, la habitación de los eclesiásticos era amplia y confortable, con pocas camas sólo las que ocupasen los curas con mesas y sillas. La decoración era austera, gravosa y elegante. Primaba el silencio y la tranquilidad. Habitación aislada de miradas extrañas, incluso era puntual el ingreso del enfermero. Este cuarto estaba en el otro extremo de la enfermería femenina y del ir y venir de enfermeras y lamentos de las enfermas. De acceso restringido, ni siquiera del enfermero quien sólo entraba contadas veces a la habitación para no perturbar a los ancianos. La enfermería de clérigos tenía un patio con estante de agua que se renovaba. ${ }^{19}$

18 ADPS. Justificantes de entrega en depósito al Museo Provincial de Bellas Artes de Sevilla por parte del Hospital Central de las Cinco Llagas de varios cuadros (entre ellos nueve del pintor Zurbarán). En la enfermería de eclesiásticos había cuadros de Murillo y Zurbarán.

19 Jiménez Martin, Alfonso, Op. cit, p. 225. En 1628 se ingreso agua al hospital. 


\begin{tabular}{|c|c|c|}
\hline \multirow[t]{2}{*}{1699} & 1711 & 1726 \\
\hline & $\begin{array}{l}\text { Un lienzo de dos varas y } \\
\text { media de alto con la efigie } \\
\text { de Nuestro Padre San Pedro, } \\
\text { pintura de Murillo con } \\
\text { moldura de tercia de ancho } \\
\text { con arquitrabe y orla de } \\
\text { cascarilla toda dorada menos } \\
\text { las medias cańas que son } \\
\text { negras. Y todo está nuevo y } \\
\text { vale muchos pesos por ser de } \\
\text { tal pintor }\end{array}$ & \\
\hline $\begin{array}{l}\text { Dos cuadros, el uno de la } \\
\text { cena y el otro de las Cinco } \\
\text { Llagas ambos viejos }\end{array}$ & $\begin{array}{l}\text { Dos lienzos tendidos de } \\
\text { vara y media: uno de la cena } \\
\text { y otro de la Asunción de } \\
\text { Nuestra Seńora. Viejos y } \\
\text { bastos } \\
\text { Otro lienzo de vara de alto } \\
\text { con las Cinco Llagas }\end{array}$ & $\begin{array}{l}\text { Dos Lienzos tendidos de } \\
\text { vara y media : uno de la } \\
\text { cena, otro de la Asunción } \\
\text { de Nuestra Señora. Viejos } \\
\text { y bastos } \\
\text { Otro lienzo de vara de alto } \\
\text { sin moldura con las Cinco } \\
\text { Llagas }\end{array}$ \\
\hline $\begin{array}{l}\text { Una hechura de un Santo } \\
\text { Cristo de madera en su } \\
\text { cruz con su peana, muy } \\
\text { antiguo. }\end{array}$ & $\begin{array}{l}\text { Un crucifijo de bulto con } \\
\text { peana. }\end{array}$ & $\begin{array}{l}\text { Dos lienzos de vara y media } \\
\text { de alto: uno de la Soledad } \\
\text { y otro de la Magdalena, } \\
\text { viejos. }\end{array}$ \\
\hline \multirow{2}{*}{$\begin{array}{l}\text { Un cuadro de Nuestra } \\
\text { Seńora del Rosario } \\
\text { pequeńo con su marco } \\
\text { viejo y otro de Santa } \\
\text { María Magdalena. }\end{array}$} & $\begin{array}{l}\text { Dos varas y media de alto el } \\
\text { uno de la Soledad y el otro } \\
\text { de la Magdalena, mediados. }\end{array}$ & $\begin{array}{l}\text { Un lienzo de dos tercias de } \\
\text { alto, las dos con moldurillas } \\
\text { negras maltratadas de } \\
\text { nuestra Señora del Rosario. }\end{array}$ \\
\hline & $\begin{array}{l}\text { Dos lienzos de vara de alto } \\
\text { el uno Nuestra Señora del } \\
\text { Pópulo y el otro de Santa } \\
\text { Rosa. }\end{array}$ & \\
\hline $\begin{array}{l}\text { Tres cuadros: uno de } \\
\text { San Cayetano, otro del } \\
\text { Santísimo Sacramento y el } \\
\text { otro de nuestra Señora del } \\
\text { Populo, viejos. }\end{array}$ & $\begin{array}{l}\text { Tres lienzos de dos tercios de } \\
\text { alto, los dos con moldurilla } \\
\text { negras maltratados el uno } \\
\text { de Nuestra Sra. del Rosa y el } \\
\text { otro de Belén, y el tercero de } \\
\text { San Cayetano bien tratado y } \\
\text { sin moldura. }\end{array}$ & $\begin{array}{l}\text { Dos lienzos: El segundo de } \\
\text { Nuestra Señora del Belén y } \\
\text { el otro de San Cayetano sin } \\
\text { molduras y maltratado }\end{array}$ \\
\hline
\end{tabular}




\begin{tabular}{|c|c|c|}
\hline & $\begin{array}{l}\text { Tres cruces: dos dentro de } \\
\text { la enfermería y otra mayor } \\
\text { sobre la puerta de afuera que } \\
\text { sale hacia el corredor. }\end{array}$ & $\begin{array}{l}\text { Tres cruces de madera } \\
\text { bastas muy usadas, la mayor } \\
\text { está sobre la puerta delante } \\
\text { de enfermería que sale al } \\
\text { corredor alto y las otras dos } \\
\text { de a media vara. }\end{array}$ \\
\hline & $\begin{array}{l}\text { Dos sillones muy viejos el } \\
\text { uno todo el asiento de tabla } \\
\text { y sin baqueta ni clavazón y el } \\
\text { otro de baqueta negra }\end{array}$ & $\begin{array}{l}\text { Un sillón muy viejo con el } \\
\text { asiento de tabla sin baqueta }\end{array}$ \\
\hline $\begin{array}{l}\text { Cuatro camas de bancos } \\
\text { de borde y pies de hierro y } \\
\text { cuatro tablas cada una }\end{array}$ & $\begin{array}{l}\text { Un encerado o guardapolvo } \\
\text { en bastidor de } 3 / 4 \text { en cuadro } \\
\text { por la ventana de la dicha } \\
\text { ante enfermería alta }\end{array}$ & $\begin{array}{l}\text { Un encerado sin bastidor } \\
\text { para la ventana de la ante } \\
\text { enfermería }\end{array}$ \\
\hline $\begin{array}{l}\text { Tres bancos de pino sin } \\
\text { espaldar viejos. }\end{array}$ & $\begin{array}{l}\text { Dos bancos de a dos varas. } \\
\text { Uno de pies torneados y otro } \\
\text { de pies de tabla. }\end{array}$ & $\begin{array}{l}\text { Dos bancos de a dos varas } \\
\text { de largo de borde. Uno de } \\
\text { pies torneados y otro de pies } \\
\text { de tabla. }\end{array}$ \\
\hline $\begin{array}{l}\text { Seis banquillos de pino } \\
\text { y uno de ellos con dos } \\
\text { puertillas que sirven de } \\
\text { alacena. }\end{array}$ & $\begin{array}{l}\text { Cinco banquillos de } \\
\text { asentarse de } 3 / 4 \text { de largo unos } \\
\text { más altos que otros. }\end{array}$ & $\begin{array}{l}\text { Cinco banquillos de } \\
\text { sentarse de tres cuartas de } \\
\text { largo unos más altos que } \\
\text { otros. }\end{array}$ \\
\hline $\begin{array}{l}\text { Una mesilla pequeña de } \\
\text { pino }\end{array}$ & $\begin{array}{l}\text { Una mesita de } 3 / 4 \text { de largo con } \\
\text { una gavetilla toda muy vieja }\end{array}$ & $\begin{array}{l}\text { Una mesita de tres cuartas } \\
\text { de largo con una gavetilla }\end{array}$ \\
\hline \multirow[t]{2}{*}{ Tres silletas de paja } & Dos silletas viejas de paja & \\
\hline & Un candelero velador de palo & $\begin{array}{l}\text { Un candelero velador de } \\
\text { madera }\end{array}$ \\
\hline \multirow[t]{2}{*}{$\begin{array}{l}\text { Un velador con dos } \\
\text { candiles }\end{array}$} & $\begin{array}{l}\text { Dos candiles viejos de } \\
\text { garabato }\end{array}$ & \\
\hline & $\begin{array}{l}\text { Una copa toda de cobre } \\
\text { hechura de campana }\end{array}$ & $\begin{array}{l}\text { Una copa con su pie toda } \\
\text { de cobre }\end{array}$ \\
\hline $\begin{array}{l}\text { Dos cacillos de mano para } \\
\text { calentar aceites } \\
\text { Dos lebrillos vidriados } \\
\text { para sangrar. }\end{array}$ & $\begin{array}{l}\text { Cuatro pares de bancos de } \\
\text { cama de palo con pies de } \\
\text { fierro y doce tablas }\end{array}$ & $\begin{array}{l}\text { Seis pares de bancos de } \\
\text { cama de palo con pies de } \\
\text { fierro y dieciséis tablas } \\
\text { para dichos bancos en } \\
\text { que se incluye la cama del } \\
\text { enfermero }\end{array}$ \\
\hline
\end{tabular}




\begin{tabular}{|l|l|l|}
\hline $\begin{array}{l}\text { Una cama de dos bancos } \\
\text { de borne pies de hierro } \\
\text { y cuatro tablas, dos } \\
\text { colchones, dos sábanas, } \\
\text { dos almohadas y un } \\
\text { cobertor de pelo pardo } \\
\text { para dormir del enfermero. }\end{array}$ & $\begin{array}{l}\text { Un de bancos como los de } \\
\text { arriba con cuatro tablas que } \\
\text { fueron para hacer su cama } \\
\text { el enfermero, dos colchones, } \\
\text { dos almohadas y dos sábanas }\end{array}$ & $\begin{array}{l}\text { Dos colchones, dos sábanas, } \\
\text { dos almohadas, y un } \\
\text { cobertor para la cama usual } \\
\text { del enfermero }\end{array}$ \\
\hline $\begin{array}{l}\text { Tres tarimas de tres tablas } \\
\text { cada una con sus pies }\end{array}$ & $\begin{array}{l}\text { Una tarima con cuatro tablas } \\
\text { y tres pies de lo mismo. }\end{array}$ & Tres tarimas de cuatro tablas \\
\hline & $\begin{array}{l}\text { Unos pies de tijera para mesa } \\
\text { con cadena de fierro y le falta } \\
\text { la tabla a la mesa. }\end{array}$ & $\begin{array}{l}\text { Unos pies de tijera para una } \\
\text { mesa muy viejos con cadena } \\
\text { de fierro y no tiene la tabla } \\
\text { para dicha mesa }\end{array}$ \\
\hline $\begin{array}{l}\text { ADPS. Legajo 1A. Libro de inventario de bienes muebles del Hospital de la Sangre de } \\
\text { Sevilla. 1699. Libros inventarios } 1625 \text { y 1726. }\end{array}$
\end{tabular}

\section{El área femenina de incurables del Hospital de la Sangre}

El hospital tenía prohibido recibir mujeres incurables, pero la realidad se impuso y empezó a cobijar primero a sus hospitaleras que habían entregado su vida trabajando en él. En el siglo XVI, se acomodaron a las incurables con la enfermas de enfermería, pues no se había habilitado una habitación exclusiva para ellas. La demanda de camas de incurables, ya no sólo provenía de las trabajadoras del hospital, sino de otras enfermas en esa condición. Sabedora de esta realidad y necesidad que tenía el hospital, Dońa María de Torres, mujer del jurado Gaspar de Ávila Alvasajado, destinó en su testamento 20.000 ducados para 20 camas asignadas a incurables en 1620, quedando constatada en la constitución de $1624 .{ }^{20}$ La necesidad era tanta que otra dotación se orientó a este fin en 1622 por Joan Agustín Montalvo quien donó 300 ducados de renta para el sustento de mujeres incurables del hospital por dos años después de la muerte de doña Jerónima de Grimaldo. Esta donación se situó en un juro de 112.500 maravedíes de renta en las alcabalas de la ciudad de Sevilla. ${ }^{21}$ Esta área fue creciendo en importancia a medida que pasaban los siglos hasta el grado de hacerse imprescindible por la gran

20 Banda de Vargas, Antonio de la. Las Cinco Llagas. De hospital a Parlamento de Andalucía. Sevilla: Secretaria General Parlamento de Andalucía, 2007, p. 22. Gracias al legado realizado por María de Torres de 20,500 ducados se habilitaron 20 camas para incurables. ADPS. Legajo 4B. Libro de juntas capitulares de 1616 a1637, f. 21 r-v, f.23 r-v, f.14 r.( 1620).

21 ADPS. Ibídem, f. 34 r (1622). AHPS (Archivo Histórico Provincial de Sevilla) Protocolos. Escribano público de Sevilla Joan Batista de Contreras, 29 de julio de 1622. Manda testamentaria de Agustín de Montalvo fue aceptada por los patrones del hospital, usando de la facultad apostólica conferida y mandaron que se tomara razón en los libros del hospital. 
demanda de sus camas. Todo esto se desarrolló a pesar de la tácita prohibición en los reglamentos del hospital de recibir incurables. ${ }^{22}$

En el periodo de 1600 a 1620, la sala de San Pedro o de enfermas comunes albergó a enfermas agonizantes, heridas e incurables. En esta enfermería había 20 tarimas altas con dos colchones, dos sábanas, dos almohadas y dos cobertores de pelo. ${ }^{23}$ De esta manera, la enfermería solía hacerse cargo de las nuevas especialidades, cediendo espacio y mano de obra hasta que se designaran sus propias servidoras y construían las nuevas salas a ocupar. ${ }^{24}$ En la constitución de 1624, indica que la enfermera mayor, si bien, estaba orientada para las enfermas de medicina, contando con la ayuda de cinco ayudantas, en realidad cuidaban a las enfermas de diferentes salas o cuartos como: la sala de convalecencia, la sala de incurables, la sala de calenturas, la sala de convulsiones y otras. Esta situación continuó entre 1620 a 1639 cuando se estaban estableciendo las camas de incurables y convalecientes. La madre enfermera y sus doncellas tuvieron que asumir estas tareas hasta que se nombraron las madres y doncellas incurables y convalecientes por sus benefactores. Después de este periodo, la madre enfermera y sus cinco doncellas volvieron a restringirse solamente a la atención de la sala de enfermerías o San Pablo.

Después de 1639, las mujeres incurables se ubicaron en las salas altas y bajas del área de agonizantes, llamada de San Pablo, por lo cual fueron atendidas por la madre agonizante. Es por esta razón que las primeras camas de incurables para hospitaleras del hospital fueron designadas a las que ayudaban a asistir a las enfermas agonizantes. Ya en 1699, las incurables ya tenían un cuarto propio, muy cerca al área de convalecientes de mujeres. ${ }^{25}$ Las hospitaleras de convalecencia atenderían en esa época a las incurables.

Los médicos visitaban a las enfermas de enfermería, cirugía e incurables y debían llegar a sus horas para pulsar y recetar la medicación a todas, para evitar que muriesen sin sacramento. En el siglo XVIII, muy raras veces, la enfermería de San Pedro acogía a las enfermas incurables, lo que estaba prohibido por reglamento, salvo excepciones cuando los patronos del hospital lo permitían, recibiendo mujeres ancianas a cambio de alguna donación como una casa. En 1770 se recibió en una de las camas comunes de enfermas, y no en la enfermería de incurables, a Josepha Álvarez de 60 años, vecina de Sevilla, soltera y pobre. Donaba a cambio

22 ADPS, legajo 1, Constitución de 1503, Constitución de 1603, Constitución de 1624. Biblioteca Colombina( B.C.), fondo Gestoso, Constitución del hospital de la Sangre de 1734.

23 ADPS. Legajo 1A. Libro de inventario de bienes muebles del Hospital de la Sangre de Sevilla,folios 273 y 274 (1636).

24 ADPS. Legajo 4B. Libro de juntas de 1620, f.21 r. No se construyó sala alguna de incurables porque María de Torres dio 20.000 ducados para sólo la manutención de las camas.

25 ADPS. Legajo 1A. Libro de inventario de bienes muebles del Hospital de la Sangre de Sevilla, folios 110, 111 (1699). 
una casa. ${ }^{26}$ En 1781, se recibió a Isabel de Escobar, en separación del común de las enfermas, pagando por ello tres reales de vellón diarios. ${ }^{27}$

\subsection{La "madre incurable" y sus doncellas del área fémina de incurables}

Generalmente, este cargo se asignaba a las hospitaleras que habiendo trabajado mucho tiempo en el hospital se hacían merecedoras a tal cargo. La madre de incurables no tenía que trajinar mucho. Este cargo era tan solicitado que existía una larga lista de espera, con las llamadas madres incurables supernumerarias, nombrándose a algunas, cuando vacaba una plaza. Era el cargo femenino más solicitado de entre todos los que ofrecía el hospital.

Existían diversas maneras de acceder a una plaza de madre incurable:

1.- Una madre con muchos años en el hospital podía ser acreedora a una de estas plazas que exigía poco trabajo. Recibía salario reducido y ración de comida. Este cargo era muy apetecido por todas las madres al llegar a edad longeva porque significaba trabajar menos. Se encargaban de la atención de las 20 incurables que recibía el hospital

2.- Una hospitalera al jubilarse le asignaban una cama de incurables. Le daban un salario de jubilada, ración de comida diaria y ayuda de costa de 12 reales por mes para calzado y vestido, se la nombraba para una cama de incurable y recibía un salario reducido. ${ }^{28}$

3.- Una hospitalera enferma recibía una cama donde pasar sus últimos días. Podía ostentar el título de madre incurable, pero como no trabajaba y no había logrado jubilarse, no cobraba salario.

4.- Mujeres externas al hospital que solicitaban el ingreso como madre incurable a través de memoriales o solicitudes a los priores del hospital. Se trataba de mujeres que no habían trabajado en el hospital, pero que compraban este cargo con bienes patrimoniales. Mujeres viejas y enfermas sin curación, pero no moribundas, accedían a estas camas que eran muy apetecidas. Algunas pagaban su mantenimiento entregando sus casas al hospital bajo testamento o dinero en efectivo. Alguna mujer accedía a estas camas por recomendación de algún personaje influyente que beneficiaba al hospital como un personaje de la nobleza, del cabildo o del alto clero. Por ejemplo: a fines del siglo XVIII, concretamente en 1783 se dio ese cargo a Francisca Martínez, soltera, dando por ello la adjudicación de una casa: "Por otro memorial dado por Dońa Francisca Martínez de estado honesto, se reciba en cama de incurable siempre que se verifique la propiedad

26 ADPS. Legajo 4B. Libro de Auto Capitulares del Hospital de la Sangre, de 1764 a 1787, f.34 r (1770).

27 ADPS. Ibidem, f.113 v (1781).

28 ADPS. Libro de juntas o actas capitulares de patronos del Hospital de las Cinco Llagas (1687-1715), f. 36 v (1693). 
de la casa que ofrece, y la adjudicación de ella a este hospital en forma legítima en calidad de futuraria ${ }^{29}$ de madre incurable con derecho a la primera plaza que vaque y entretanto se le dará la ración acostumbrada". ${ }^{30}$

Así se observa que había diferentes formas de acceso a una cama de incurables, pero tenía una peculiaridad en común, tenían que ser mujeres solas que no tuviesen otras obligaciones, ni familia. Viudas o solteras.

En los libros del Hospital de la Sangre se han detectado poquísimos casos de madres incurables y ayudantes que trabajaron recibiendo un salario por ello. En los libros del Hospital de la Sangre se han detectado poquísimos casos de madres incurables y ayudantes que trabajaron recibiendo un salario por ello. Una de las mas antiguas en ser mencionadas fue la viuda Ana de Campos en 1696, otra fue Isabel de Duque trabajó desde 1722 a 1740. En los testamentos se han hallado los nombres de las siguientes madres incurables.

Tabla 2: Una breve relación de algunas madres incurables, el tiempo que ejercieron, estado, procedencia, los bienes que poseían y sus últimas voluntades testamentarias.

\begin{tabular}{|l|l|l|l|l|}
\hline Nombre & Oficio & Estado & Muerte & Natural \\
\hline $\begin{array}{l}\text { Ana de } \\
\text { Campos }\end{array}$ & Madre cirujana(1679 a 1693) & $\begin{array}{l}\text { Viuda de } \\
\text { Manuel } \\
\text { Gonzáles }\end{array}$ & 1695 & Arriaga \\
& $\begin{array}{l}\text { Madre jubilada ejerció de Madre } \\
\text { Incurable (1693-1695) }\end{array}$ & & \\
\hline
\end{tabular}

Al quedar viuda empezó a trabajar en el hospital. Tenía una sobrina, huérfana, que vivía con ella, a la que el hospital le daba una libra de pan diaria hasta que entró como doncella de dote del hospital. ${ }^{1}$ Ana Campos llegó a ser madre cirujana jubilada. En la junta de 19 de Febrero de 1693 mandaron los patronos priores del hospital jubilar a Ana Campos y le dieron cama de incurable y mandaron que se le diese ayuda de costa de 12 reales mensualmente, desde 1694 a 1696 cuando murió. En su testamento mandó: 50 misas en el Convento de San Benito de donde fue hermana de la cofradía y hermandad de Nuestra Señora del Socorro y 50 misas rezadas en el Convento Regina Angelerum en la capilla de Nuestra Señora del Rosario. Dejaba lo no cobrado de su salario para el entierro y misas, y lo que sobrase para el adorno del Santísimo Sacramento de la enfermería del hospital. Toda su ropa la dio a su sobrina Josepha María, quien había sido doncella de dote de hospital. Se le descontó su entierro de su salario ahorrado. Se pagaron 39 reales a la sobrina de Ana Campos, dinero que el hospital le debía. Le dejó también una muleta "muy rica" que usaba. Fue enterrada en la iglesia del hospital.

29 Futuraria: propio de la futura o de la persona que posee el derecho a la sucesión de un empleo antes de estar vacante. En: Enciclopedia Universal ilustrada Europeo Americana. Barcelona. Hijos de J. Espasa Editores. 1924. Tomo XXV, p. 322.

30 ADPS. Legajo 4B. Libro de Auto Capitulares del Hospital de la Sangre de 1764 a 1787, f.125 r (1783). 


\begin{tabular}{|c|c|c|c|c|}
\hline $\begin{array}{l}\text { María de } \\
\text { Alarcón }\end{array}$ & $\begin{array}{l}\text { Madre agonizante (1684 a 1692) } \\
\text { Madre incurable(1697) } \\
\text { Madre agonizante jubilada en } 11 \text { de } \\
\text { febrero de } 1693 \text { sin salario alguno. }\end{array}$ & $\begin{array}{l}\text { Viuda de } \\
\text { Pedro de } \\
\text { Osorio }\end{array}$ & 1697 & $\begin{array}{l}\text { S a n t a } \\
\text { Olalla }\end{array}$ \\
\hline \multicolumn{5}{|c|}{$\begin{array}{l}\text { Al enviudar se dedicó a trabajar en la hospitalidad por muchos años. Fue enterrada en la } \\
\text { iglesia del hospital. Velación con seis acompañados con } 2 \text { libras de cera y trescientas misas } \\
\text { por su alma a dos reales cada una en los tres conventos de los patronos del hospital. No } \\
\text { se realizó almoneda, pues sus bienes se los cedió a una viuda. Una hechura de Jesús lo dio } \\
\text { a la sacristía. Donó } 40 \text { pesos para ropa de lienzo, destinado a las enfermerías y } 50 \text { reales } \\
\text { de vellón que se le dio a la madre mayor, responsable de la adquisición de corporales y } \\
\text { purificadores para la iglesia y la sacristía del hospital. También, mandó realizar misas en el } \\
\text { hospital a tres reales cada uno. }\end{array}$} \\
\hline $\begin{array}{l}\text { Dominga } \\
\text { Rodríguez }\end{array}$ & $\begin{array}{l}\text { Madre incurable(1681-1693) } \\
\text { Madre incurable jubilada con cama y } \\
\text { salario (1694-1699) }\end{array}$ & $\begin{array}{l}\text { Viuda de } \\
\text { Domingo } \\
\text { González }\end{array}$ & 1699 & Galicia \\
\hline \multicolumn{5}{|c|}{$\begin{array}{l}\text { Al morir fue enterrada en la iglesia del hospital. Velación con ocho acompañantes de la } \\
\text { iglesia de San Gil. Hábito de la orden tercera de San Pedro de Alcántara, pańo y cera que } \\
\text { daban a las hermanas terceras. Donó } 50 \text { reales para el retablo de Nuestra Señora de Belén } \\
\text { y mandó dar dinero para } 50 \text { misas en la parroquia de San Gil por el alma de su esposo. } 50 \\
\text { misas en el convento de Montesión, } 50 \text { misas en el convento San Pedro de Alcántara en la } \\
\text { capilla de la orden tercera y } 50 \text { misas en el convento del Carmen. No se realizó almoneda, } \\
\text { pues entregó todos sus bienes a su hermana. El pago de las misas fue con el salario que le } \\
\text { debía el hospital como madre incurable. Donó un colchón al hospital. }\end{array}$} \\
\hline $\begin{array}{l}\text { Mariana } \\
\text { de San } \\
\text { Joseph }\end{array}$ & Madre incurable & $\begin{array}{l}\text { Viuda de } \\
\text { Miguel de } \\
\text { Almodóvar }\end{array}$ & 1703 & Granada \\
\hline \multicolumn{5}{|c|}{ Almoneda de sus bienes para realizar misas y pagar su entierro } \\
\hline \multicolumn{2}{|l|}{ Bienes } & \multicolumn{2}{|c|}{ Persona que lo adquirió } & Dinero \\
\hline \multicolumn{2}{|c|}{ Unas naguas de bayeta } & \multicolumn{2}{|c|}{$\begin{array}{l}\text { Madre convaleciente } \\
\text { Calderón }\end{array}$} & 4 reales \\
\hline \multicolumn{2}{|c|}{ Una sábana y cobertor viejo } & \multicolumn{2}{|l|}{ Hospital } & 6 reales \\
\hline \multicolumn{2}{|l|}{ Una arca } & \multicolumn{2}{|c|}{ Madre de Fuentes } & 8 reales \\
\hline \multicolumn{2}{|c|}{ Un poco de hilo, agujas y daguilla } & \multicolumn{2}{|c|}{$\begin{array}{l}\text { Madre tornillera } \\
\text { Rudens }\end{array}$} & 1 real \\
\hline \multicolumn{2}{|c|}{ Una camisa } & \multicolumn{2}{|l|}{ Juan Gordillo } & 2 reales \\
\hline \multicolumn{2}{|c|}{ Una camisa } & \multicolumn{2}{|c|}{ María Carrasco } & 2 reales \\
\hline \multicolumn{2}{|c|}{ Unos trapos } & \multicolumn{2}{|l|}{ María Muñoz } & $1 \mathrm{real}$ \\
\hline
\end{tabular}




\begin{tabular}{|c|c|c|c|c|}
\hline \multicolumn{2}{|l|}{ Unas naguas } & \multicolumn{2}{|c|}{$\begin{array}{l}\text { Madre cocinera María } \\
\text { de la Vega }\end{array}$} & $1 \mathrm{real}$ \\
\hline \multicolumn{2}{|c|}{ Una mantilla } & \multicolumn{2}{|l|}{ Juana Ramos } & $1 \mathrm{real}$ \\
\hline \multicolumn{2}{|c|}{ Un cuadro y un bufetillo } & \multicolumn{2}{|c|}{ Madre de Fuentes } & 6 reales \\
\hline \multicolumn{2}{|c|}{ Una crucecita } & \multicolumn{2}{|c|}{$\begin{array}{l}\text { Madre tornillera } \\
\text { Rudens }\end{array}$} & 2 reales \\
\hline \multicolumn{2}{|l|}{ Un anillo } & \multicolumn{2}{|l|}{$\begin{array}{l}\text { Madre portera } \\
\text { Polvorosa }\end{array}$} & 2 reales \\
\hline \multicolumn{2}{|c|}{ Dos platillos de una tasa } & \multicolumn{2}{|l|}{ Madre Pérez } & 1 real \\
\hline \multicolumn{2}{|c|}{ Un agnus guarnecido en plata } & \multicolumn{2}{|l|}{ Madre Pérez } & 7 reales \\
\hline $\begin{array}{l}\text { Andrea de } \\
\text { Salazar }\end{array}$ & $\begin{array}{l}\text { Madre incurable(1711-1714) } \\
\text { No ejerció, ocupó cama de incurables } \\
\text { previo pago mensual. }\end{array}$ & $\begin{array}{l}\text { Viuda de } \\
\text { Juan Ladrón } \\
\text { de Guevara }\end{array}$ & 1714 & Sevilla \\
\hline \multicolumn{5}{|c|}{$\begin{array}{l}\text { Andrea de Salazar, hidalga, que llevaba el título de madre, pero no ejerció, sino ocupaba } \\
\text { una cama de incurables del hospital que su sobrino Manuel de Torres, regente de la Real } \\
\text { Audiencia de Sevilla y el arzobispo de Sevilla habían adquirido en } 1711 \text {, con la condición de } \\
\text { que abonarían cada mes } 24 \text { reales para su manutención. Murió en } 1714 \text {, siendo enterrada } \\
\text { en la iglesia del hospital. Declaró tener una imagen de la Señora de Belén que entregó a su } \\
\text { confesor cura del Hospital del Amor de Dios. Un collar engastado en plata, un barquito, } \\
\text { una esterita y un pergamino de seda de Miguel Mañara que dio a la madre mayor. Lienzo } \\
\text { de San Miguel a la madre incurable Antonia Falcón, dos pañuelos de estopilla, servilletas, } \\
\text { bufetillo y cuadrito a la madre agonizante, una camisa, unas naguas blancas, una toalla } \\
\text { a la madre enfermera, una esterita de esparto a la madre cirujana y un rosario a la madre } \\
\text { ropera. Declaró tener una caja de plata, una cuchara, una mantilla azul de bayeta, un velón } \\
\text { de peltre, un cofre, una arquita dados a Leonor María Díaz y María la Rosa por haberlas } \\
\text { criado. Declaró un manto, una basquina de lamparilla y otra de tafetán y los demás bienes } \\
\text { para misas y entierro. }\end{array}$} \\
\hline $\begin{array}{l}\text { María } \\
\text { de Jesús } \\
\text { Padilla y } \\
\text { Salvatierra }\end{array}$ & Madre incurable & & 1750 & \\
\hline \multicolumn{5}{|c|}{$\begin{array}{l}\text { Vivió muchos años en el convento de la Encarnación de Sevilla. Pidió ser sepultada en la } \\
\text { iglesia del hospital según voluntad de sus amos Dn. Gabriel y Gregoria Teresa Torres de } \\
\text { Navarra quienes ofrecieron pagar los derechos. La almoneda dio para } 79 \text { misas a tres reales. } \\
\text { Nombró como albaceas a su amo, a la madre mayor y al administrador del hospital. Fue un } \\
\text { caso especial, sus amos pagaban su manutención. }\end{array}$} \\
\hline $\begin{array}{l}\text { Bernarda } \\
\text { Bonilla }\end{array}$ & Madre incurable & $\begin{array}{l}\text { Viuda de } \\
\text { Manuel } \\
\text { González }\end{array}$ & 1780 & Sevilla \\
\hline
\end{tabular}


Entregó sus bienes a su sobrino Juan Bonilla. Bernarda regaló ropa a la doncella de dote Bárbara Reinoso, a la vagante Teresa de Cárdenas y a la madre convaleciente Teresa Otaudi, las que le atendieron durante su enfermedad. Almoneda con pocos bienes para 32 misas.

\begin{tabular}{|l|l|l|l|l|}
\hline $\begin{array}{l}\text { Leonor } \\
\text { Fernández }\end{array}$ & Madre incurable & & 1795 & \\
\hline
\end{tabular}

Los gastos del entierro se los dio al obispo Don Agustín Aiestaran. Fue enterrada en la iglesia del hospital y al morir la asistió para su entierro el prioste de la hermandad del Rosario de la parroquia de Omnium Santorum.

Fuente: ADPS. Legajo 263. Memorias, testamentos, almonedas de bienes de difuntos, siglos XVI-XVIII. ADPS. Libro 207. Libro de testamentos y memorias de enfermas del Hospital de la Sangre(1693-1763)

En la constitución de 1734, "madre de convaleciente e incurable" era quien supervisaba a las dos doncellas destinadas a dicha área con tal que una de ellas, había de ser de las cuatro destinadas para el lavado de la ropa en la enfermería de ropería. Las dos doncellas eran pagadas y dotadas por el patronato Diego de Yanguas. Las funciones de todas ellas eran asistir a las mujeres convalecientes e incurables "y tendrá gran cuidado de que se les de la comida a sus horas, hacerles las camas, y todo lo demás, que la madre mayor les distribuyere; y recibo de camas de incurables". ${ }^{31}$ Pone abierta la posibilidad de agregar unas camas de enfermas incurables en la sala de convalecientes. Lo que sí ocurrió, pero nunca bajo el cuidado de una "madre convaleciente e incurable", sino con su propia "madre incurable". Así y todo, hubo cierta relación entre convalecientes e incurables, pues el que pagaba al cura de incurables era el mencionado patronato Diego de Yanguas del área de convalecencia. Incluso, se había nombrado a la madre incurable y dos doncellas. ${ }^{32}$

Las mujeres que deseaban trabajar como madres incurables mandaban un memorial en el que pedían este deseo a los patronos del hospital. Así se ha encontrado la única constancia de ingreso de una madre en los casi tres y medio siglos de existencia de este hospital, datada en 1794, con el título de

"Se recibe a Dña. María del Coral como madre incurable supernumeraria. Primeramente que a Dńa. María del Coral Andrade viuda de Dn. Joseph de Benjumeda, se le conforme a la representación que en su memorial hacía, y su caritativo deseo de servir a las pobres de sus enfermerías en cuanto lo permitieren sus fuerzas una plaza de Madre Incurable supernumeraria de el". ${ }^{33}$

31 B.C. Constitución del Hospital de las Cinco Llagas de 1734. Const. ${ }^{\circ 38 . ~ F o n d o ~ G e s t o s o ~}$ V. Art ${ }^{\circ} 115$ de 1734 .

32 ADPS. Acta capitular del año de 1658, f. 212 r-v.

33 ADPS. Legajo 4C. Libro de Auto Capitulares del Hospital de la Sangre, de 1788 a 1800 f. 50 r (1794). 
El caso de María del Coral y Andrade, natural de Sevilla, viuda de Dn. Blas Josef Díaz de Benjumea, vecino y del comercio de la ciudad solicitó ser madre incurable sin recibir salario por ello, pues disfrutaba de una holgada situación económica. En 1794, el cura semanero anotó en el libro de ingresos de enfermas: "desprendiéndose de las conveniencias que disfrutaba en sus casas y dejando en sus hijos el fijo del comercio que seguía, deseosa de acabar los días de su vida en este Santo Hospital y en la asistencia de sus pobres enfermas en la parte, que voluntariamente pudiese a los 27 días del mes de enero del año de 1794 se retiró a este hospital, ocupando la plaza de madre incurable supernumeraria cuya gracia hicieron los Reales Patronos de este Santo Hospital en 17 de dichos". ${ }^{34}$ Es interesante la anotación "se retiró a este hospital", indicando claramente la característica propia de este hospital de "casa de reclusión", por albergar mujeres legas que renunciaban voluntariamente a su vida anterior para vivir asistiendo a las enfermas. ${ }^{35}$

En 1802, se presentó un memorial de Isabel de Acosta, viuda de Diego García Moreno, alarife del hospital, solicitando una plaza de incurable, pedido que se aceptó cuando hubiere lugar ${ }^{36}$.

A comienzos del siglo XIX, el área de incurables del Hospital de las Cinco Llagas continuaba siendo una de las más apetecibles tanto por las madres que estaban a punto de jubilarse como por otras mujeres. Es indudable que en esta área no se trabajaba tanto como en las demás áreas del hospital y el tratamiento de los patronos del hospital hacia ellas era de deferencia, principalmente con las madres ancianas que habían dado su vida al hospital. Los patronos del hospital solían premiar la fidelidad a la institución y tener mucha consideración y desprendimiento con el personal que había entregado su vida a su servicio. Reconocimiento que alcanzaba inclusive a sus familias, al amparar a madres, hijas, esposas, sobrinas de los trabajadores que se entregaron al hospital.

Esta área era distinta a las demás enfermerías ya que en 1804, las madres incurables que trabajaban allí, Rafaela Franco y Ana de Lara, solicitaron poder ahorrar en sus salarios las raciones de comida que no comían, para poder obtener más dinero, cosa que era una práctica común para todas las madres y doncellas

34 ADPS. Legajo 248. Libro de entrada y salida de enfermos de 1766 a 1798, f.273 $\mathrm{v}(1794)$.

35Gómez García, María del Carmen. "Trabajo y actividades de las religiosas en los conventos malagueños (s. XVIII)”, en Matilla, M. y Ortega, M. (eds.), El trabajo de las mujeres: siglos XVI- XX. Madrid: Universidad Autónoma de Madrid, 1996, pp.113. La analogía entre un convento y el Hospital de la Sangre es evidente. Por ejemplo: la enfermería era el lugar reservado a la clausura y dedicado al cuidado de las monjas que padeciesen algún mal físico o de las más ancianas que por los achaques y limitaciones propios de la vejez, no podían realizar una actividad normal y precisaban cuidados especiales, tal es el caso de la madre perpetua sor Catalina de Fúnez, que por su avanzada edad (ochenta y nueve años) residió los últimos años de su vida en la enfermería del convento.

36 ADPS. Legajo 4C. Libro de Juntas y acuerdos capitulares de 1800 a 1831, f.23 v (1802). 
del hospital desde siglos. Además, pedían que el hospital les entregase media libra de pan diaria a mérito de haber servido muchos años en él. Todo lo pedido se les fue concedido. ${ }^{37} \mathrm{La}$ última información que tenemos sobre las madres incurables es de 1814 cuando María Rodríguez de 65 años, solicitó una plaza de incurable en las enfermerías del hospital.

Las camas de incurables solían estar ocupadas, así que había una lista de espera que se cubría cuando estaban vacantes. Se destinaban preferentemente a madres que sirviesen en agonizantes como una gratificación por las atenciones dadas hacia las enfermas en las horas postremas de sus vidas. Todo hace indicar que existía una relación directa entre el área de incurables y su atención por una madre de agonizantes. Las incurables casi no recibían atención médica, los esfuerzos estaban en la preparación para la muerte. Por esta razón algunas madres de agonizantes recibieron su salario de incurables, que pasó a pagarlo el hospital en su integridad desde 1658 38 : "mandaron que la plaza de madre agonizante que hoy hay en este hospital y corre por cuenta de una cama de incurable corra de aquí adelante por cuenta del Hospital de la Sangre y se le de ración media hogaza de pan y la carne que se da a una hija de las que sirven dicho hospital y doce reales de salario cada mes 39 "

En cuanto a las constituciones del Hospital de la Sangre, la madre de incurables no es casi mencionada, aunque existió desde 1622. La constitución de 1734 la incluye en convalecientes, pero sin ninguna relación con ella. Este cargo fue creado como una manera de amparar a las mujeres que habiendo trabajado o no en el hospital era otorgado directamente por la máxima instancia que eran los patronos priores del hospital. Aunque a fines del siglo XVIII, la persona que ocupase una de estas camas era nombrada, sin que por ello fuese necesario consultar al patrono presidente.

\subsection{La sala de incurables femenina del Hospital de la Sangre}

A pesar del ingreso monetario de 1620 para 20 camas de incurables, en 1637, se suprimieron 8 camas, quedando 12 por no poderlas sustentar con la renta que María Torres dejó para este fin por pleitos con acreedores. Se quitarían las mencionadas camas en forma secuencial a medida que se fueran muriendo las que las ocupaban. Además se ordenó no recibir a ninguna enferma de fuera para incurables. Reservado sólo para las enfermas “incurables y sin remedio” del

37 ADPS. Legajo 4C. Libro de Juntas y acuerdos capitulares de 1800a 1831, f.39 v (1804).

38 Carmona García, Juan Ignacio "Cinco siglos de historia...”, Op.cit, p. 87. El hospital se financiaba fundamentalmente con los ingresos procedentes de sus propiedades rústicas y urbanas, de los censos y juros que rentaban a su favor, de las donaciones, limosnas y otras obras pias.

39 ADPS. Libro de juntas o actas capitulares de patronos del Hospital de las Cinco Llagas, de 1637 a 1658, f.237 v (1658). 
Hospital de la Sangre. ${ }^{40}$ Los patronos acordaron en 1656 que la cama de incurables vacante se le diese a una mujer que servía de agonizante la cual fuese nombrada por el administrador. ${ }^{41}$ De esta manera, se sentó el precedente para que la ocupasen las madres enfermeras de hospital. En 1657, se enviaron a modo de jubilación a dos madres del hospital (enfermera y cirujana) y a una recomendada del prior del convento de San Isidoro ${ }^{42}$ : "A Doña Jerónima Velazquez madre enfermera del hospital y a Marina de Mora madre cirujana a cada una media hogaza de pan y $3 / 4$ de carne y $3 / 4$ de pescado el día que toque y una cama con toda ropa por los días de su vida estando en este hospital respecto de haber servido en él en dichos oficios y otros muchos años y se pongan por incurables en las primeras camas que vacasen de esta obra pía (y la siguiente que vacare) se dé al padre fray Miguel de Águila prior del convento de San Isidoro la incurable que su paternidad pidió". La madre cirujana Marina de Mora, con más de 20 años de servicio, se destinó una cama de incurables a modo de jubilación, donde continuó trabajando según sus fuerzas hasta su muerte en 1659 .

Los fondos para el mantenimiento de la cama de incurables se obtenían de legados testamentarios o lo pagaban las propias enfermas con sus bienes. La manutención de cada una de estas camas era bastante cara. Por ejemplo, en 1665 Alonso Jiménez Batres ofreció dotar dos camas para enfermas incurables de manera perpetua ${ }^{43}$ y en 1681 María de Anguieta y María Ponce dotaron dos camas y el sustento de dos enfermas de incurables. ${ }^{44}$

Toda esta área fue responsabilidad de la madre mayor. Es interesante indicar que la costumbre de albergar madres enfermeras retiradas, que se fue instituyendo en el hospital, empezó aproximadamente en 1656 cuando se dio una cama de incurables que estaba vacante a una madre que servía en agonizantes. ${ }^{45}$ De esta manera, en 1690, se dio una cama de incurables a otra madre de agonizantes donde pasar sus últimos días. ${ }^{46}$ Sin embargo en 1693, una madre cirujana solicitó

40 ADPS. Legajo 4B. Libro de juntas capitulares de 1637 a1658, f. 21 r (1638).No recibiéndose a enfermas de fuera con título de incurable mientras hubiesen en el hospital.

41 ADPS. Ibídem, f. 219 v (1638).

42 ADPS. Ibidem, f. 231 v (1638).

43 ADPS. Legajo 4B. Libro de juntas o actas capitulares de patronos del Hospital de las Cinco Llagas de 1659 a 1687, f.71 r (1665).Ramos Carrillo, Antonio,Op. cit., p. 32.

44 ADPS. Ibidem,f.162 v (1681).

45 ADPS. Legajo 4B. Libro de juntas o actas capitulares de patronos del Hospital de las Cinco Llagas de 1637 a 1658, f.219 v (1656)."Primeramente acordaron que la cama de pobres incurables que está vacante se le dé a una mujer que sirva en agonizante, la que nombre el señor administrador en quien concurran las cualidades necesarias".

46 ADPS. Legajo 4B. Libro de juntas o actas capitulares de patronos del Hospital de las Cinco Llagasde 1687 a 1715, f. 21 v (1690). "Acordaron y mandaron que María Alarcón, madre agonizante, que de presente es de este hospital se le dé la primera cama de incurables que vacare en él sin que para ello sea necesario consultar al Sr. patrono a quien toca, tocare su provisión porque desde ahora para cuando llegue el caso dicha vacante hacían e hicieren nombramiento en la dicha 
ser jubilada y la concesión de una cama de incurables que vacase. Había lista de espera, pues era "la segunda que vacare".

A las camas de incurables podía acceder cualquier enferma, pero se daba preferencia a los trabajadores del hospital y sus parientes. Así que se denegaban muchas veces los pedidos que provenían del exterior del hospital. Además había pocas camas de incurables. ${ }^{47}$

Se tenía mucha permisividad en el trato de las enfermas incurables, al grado de permitirles comer carne en los días prohibidos porque les sentaba mal otra cosa. $\mathrm{Al}$ ser personas incurables muy ancianas y enfermas no solían visitarlas el médico, sin embargo desde 1688 se determinó que lo hiciera para que se informase de sus achaques y determinase si podían comer pescado en los días prohibidos de comer otro tipo de carne. Hay que tener en cuenta que las incurables eran personas muy religiosas que habían servido en el hospital gran parte de su vida.

Las camas de incurables tenían sus propias rentas las que continuamente se ajustaban y se ponían al día, por ser muy solicitadas. Lamentablemente había pocos legados testamentarios a estas camas y sufrieron un fuerte choque económico en la crisis de 1687 a 1693. En 1694, le asignaron una cama de incurable a la madre convaleciente y jubilada Dominga Rodríguez de los Reyes que había servido muchos ańos en el hospital. ${ }^{48}$

Ya en 1697 no alcanzaba la renta para mantener y sustentar las camas con las dotaciones dejadas por varias personas, así que el hospital gastaba de su propio caudal y hacienda muchos reales. Se determinó que las camas de incurables no se volviesen a usar hasta que el secretario diese testimonio del estado de la hacienda de estas camas y de las que se podían sustentar, mantener y continuar, haciendo el tanteo de cada una a 4 reales y medio cada día para el sustento, cama, ropa, asistencias y limpieza. Posteriormente con la información recabada los patronos tomaron una decisión. ${ }^{49}$

A veces una cama de incurable ocupada por una mujer sin recursos era sustentada a través de limosnas que incluía la manutención de la enferma. Fue el caso de Antonia Falcón, viuda, acudió a la junta de patronos de 1698 para solicitar una cama de incurable que se iba a pagar con las limosnas que cada mes entregaba el arzobispo de Sevilla. Mientras se estudiaba su caso, a ella se le

María de Alarcón en la dicha cama de incurable por contar a dichos Srs. de su falta de salud y del mucho tiempo que ha estado sirviendo en el hospital .."

47 ADPS. Legajo 4B.Libro de juntas o actas capitulares de patronos del Hospital de las Cinco Llagas de 1687 a 1715, f.51 r (1695). "Peticiones de fuera: Isabel Romero. A la petición de Isabel Romero en que pide se le haga nombramiento de una cama de incurables que tiene este hospital, respondieron sus patronos no haber lugar, por estar ocupadas todas las dichas camas."

48 ADSP. Legajo 93. Libro de cuentas de convalecencia de Diego Yanguas 1677, f.282 r.

49 ADPS. Legajo 4B. Libro de juntas o actas capitulares de patronos del Hospital de las Cinco Llagas de 1687 a 1715, f.71 r-v (1697). 
designó una cama de enfermería del hospital y ración de enferma que se cobraba del situado que recibía del arzobispo. Se colocaba este ingreso en el libro de recibo y gasto en el capítulo de residuos extraordinarios del hospital. Antonia Falcón ocupó una cama de incurables desde 1698 hasta 1720 en que murió ${ }^{0}$.

En 1695 había siete camas de incurables, no aumentaron por la falta de rentas y quiebras en las dotaciones de los legados testamentarios. En el inventario 1699 se sabe que había catorce camas. Esto indica el estado de fluctuación económica del área de incurables. Sin embargo, en 1700 se había hecho liquidación de las rentas y esclarecimiento del real estado de cuenta, determinando el estado de las rentas corrientes, litigiosas y perdidas de las camas de incurables. Se sacó de conclusión que la cuenta corriente de incurables podía mantener hasta diez camas, a razón anual de 150 ducados cada una. Se determinó poner más camas si las rentas aumentaban y que el nombramiento para una de las camas se tendría que hacer previa anuencia de junta de patronos. ${ }^{51}$

A mediados del siglo XVIII, el área de incurables se disgregó por las diferentes enfermerías. Esta costumbre la implantaron las mismas madres incurables que preferían seguir ocupando las enfermerías donde habían trabajado. Esta dispersión de camas de incurables creó problemas, en un principio al hospital, para su administración. Aunque a la larga primó esta costumbre, desapareciendo la habitación de incurables. Así, en 1708, algunas de las "pobres" que asistían en el hospital y que estaban nombradas en camas de incurables, tenían sus camas y asistencia fuera de la sala que estaba señalada para ello. Por lo que los patronos ordenaron que las nombradas asistiesen, durmiesen y comiesen en la sala de incurables, no pudiendo tener las camas en otra enfermería ni cuarto del hospital. Sin embargo, los mismos patronos del hospital dieron a Luisa de Meneses, sobrina de una excelente madre mayor que sirvió muchos años en el hospital, una cama de incurables y ración en habitación aparte, siendo atendida por una sobrina. ${ }^{52}$ En este caso la madre mayor Ana de Meneses legó en su testamento la manutención de su sobrina Luisa durante toda su vida.

Otro caso notable fue María Escobar que fue sobrina del secretario y mayordomo del hospital Francisco Pérez de Escobar quien había trabajado cuarenta ańos en el hospital y además era prima del administrador Mateo de Escobar a finales del siglo XVII. Al jubilarse este administrador le dieron ración de comida y 50 ducados anuales, viviendo en una casa del hospital de la que no pagaban renta. Posteriormente, en 1696, el tío y primo de María de Escobar habían muerto, de tal manera que los patronos determinaron que mientras viviera en la ciudad de Sevilla, se le diese una limosna anual de 500 reales de vellón y 
cada día una hogaza de pan y media libra de vaca o de puerco o de pescado en los días de vigilia, con la condición que dejara la casa donde había vivido con sus parientes difuntos ${ }^{53}$. Sin embargo se la suspendieron en 1698 por la mala situación económica del hospital, entregándole sólo el dinero, sino se le devolvía la casa del hospital donde había vivido con sus parientes, teniendo que pagar su renta o sino conformarse sólo con los 500 reales que se le daban en compensación por la renuncia al derecho de la casa y las mejoras realizadas en ella. En 1701, María solicitó la entrega de su ración de comida, alegando vejez. Pedido que fue concedido. En 1711, a María de Escobar se le destinó una cama de incurables donde se le ayudaba con ración de comida, en vez del dinero que se le daba como situado. Al entregar la casa donde vivía, el hospital se comprometió a mantenerla hasta su muerte.

En 1706, se le dio una cama de incurables a la madre de convalecientes Catalina de Calderón por haberla jubilado los patrones el 31 de diciembre de $1705^{54}$. En 1708, los patronos del hospital determinaron reducir dos camas de las diez que había desde 1700, a pesar de la fuerte demanda de las mismas. Además se ordenó extinguir las demás camas a medida que vacasen debido al descenso de la renta de las dotaciones por las camas de incurables por la "la calamidad de los tiempos", falta de pago de los juros y baja de los tributos. Todas las camas tenían una dotación constante de 8.000 reales de vellón que el hospital había asumido, sustentado hasta diez camas de incurables a 150 ducados cada una anualmente y habiendo gastado una fuerte cantidad para la manutención de las camas, además de deudas considerables que había en algunas de las dotaciones. Por lo cual, para recuperar el dinero que el hospital había gastado o "suplido", se determinó la extinción de dos camas que habían vacado, no nombrándose enfermas en ellas y de las ocho que quedaban, se irían extinguiendo cuando fueran vacando hasta que el hospital pueda recuperar lo que había dado o suplido a dichas dotaciones. Se determinó que el administrador no nombrase a más enfermas a camas de incurables hasta que el hospital se haya hecho enteramente pago de dicho suplemento. Solamente podían ser nombradas las enfermas que ocupasen camas que tuviesen rentas suficientes en las dotaciones para su manutención. ${ }^{55}$

53 ADPS. Legajo 4B. Libro de juntas o actas capitulares de patronos del Hospital de las Cinco Llagas de 1687 a 1715, f.59 r (1696) “...con calidad y condición que había de hacer y haga dejación y desistimiento de la casa que tiene de por vidas en la calle del Candilejo, colación de San Ildefonso o finca del número 168 de la hacienda de este hospital, y con dicho desistimiento, renuncia de las mujeres que hubiere en dicha casa y no en otra forma ni manera y no haciéndolo así deje todo lo proveído en este auto y no corra el dar dicha situación de limosna hasta haber hecho dicho desistimiento y renuncia de mejoras de dicha casa. Y en lo que toca a la cobranza de lo que el dicho..."

54 ADSP. Legajo 93. Libro de cuentas de convalecencia de Diego Yanguas de 1695 a 1709 , f.347 r.

55 ADPS. Legajo 4B. Libro de juntas o actas capitulares de patronos del Hospital de las Cinco 
En 1709, se le asignó una cama de incurables a Josepha Bonifacia Meneses sobrina nieta de Ana de Meneses, madre mayor que murió en 1658 que había estado viviendo en el hospital en un cuarto con una sobrina de la madre mayor hasta que murió. ${ }^{56}$ Se le asignó una cama a pesar de la orden de extinción paulatina de las mencionadas camas. Ese mismo año, la madre Catalina de Calderón, que había servido en el hospital por 40 años hasta 1706, estaba en incurables cuando murió, victima de la epidemia, dejando dos testamentos, uno en el que pedía que se ajustara las cuentas de lo que se le estaba debiendo de su salario y ahorros, destinándolo todo a celebrar misas rezadas por su alma de 3 reales cada una; y otro en el que dejaba al hospital lo que le debían. La resolución a este problema lo tomó el abogado del hospital. Decidieron en 1710 dejar por heredero de sus bienes al hospital porque en el último testamento no estaba en su cabal, sano juicio y por su decrepitud.

El hospital tuvo tanta necesidad de dinero que admitió que una esclava blanca ocupase una de las camas de incurables en una época que estaba prohibido conceder más nombramientos a las mencionadas camas. En 1710, la situación económica de las camas de incurables empeoró por lo que sólo accedían a ella las que podían cubrir sus gastos de manutención y ración, como el caso de María del Espíritu Santo, turca esclava, quien pagó 500 ducados de limosna a convenio hasta que muriese, entregándosele escritura ante escribano público o instrumento de seguridad de que se mantendría en el hospital, que no se le echaría en tiempo alguno de la cama otorgada. ${ }^{57}$. Otro caso, en 1711, fue el de Andrea de Salazar, tía de Manuel de Torres, regente de la Real Audiencia de Sevilla, con la condición de que entregaría cada mes 24 reales para su manutención que lo cubría el arzobispo de Sevilla. ${ }^{58}$ Estos casos eran dispensas de los autos de no nombrar a más personas a camas de incurables hasta que se saldara la deuda de incurables al hospital.

En 1716, ya no se admitían convalecientes de otros hospitales que no fuesen de la Sangre. Existía amenaza de cierre hasta del propio hospital, así que se prohibió determinantemente el acceso a incurables. De esta manera, en 1717, los patronos visitadores jueces apostólicos del hospital habiendo reconocido los decretos y autos proveídos por los patronos del hospital para que no hubiese cama de convalecientes ni incurables a causa de no tener sus rentas congruas para estas memorias y estar debiendo estas dotaciones muchos alcances al hospital y estar a riesgo de cerrarse a causa de los atrasos, por lo que mandaron "que no se admitiera ninguna incurable, ni para tales poner cama, y si vacase alguna de las que había

Llagas de 1687 a 1715, f.163 r (1708).

56 ADPS. Ibidem, f.185 r (1709).

57 ADPS. Ibidem, f.163 r (1708), f.237 r (1710). La turca esclava vivió en el hospital desde 1710 a 1721, cuando murió. Dejó un interesante testamento en el que trataba de demostrar su religiosidad y desprendimiento monetario.

58 ADPS. Ibidem, f. 206 v (1711). 
por incurables, no se proveyese, ni se ayude para que con esto no se remplace otra en lugar de la que vacare porque la renta de incurables había llegado a tal disminución que no daba para su manutención y además daba el hospital mucha cantidad a estas dotaciones". ${ }^{59}$

A pesar de las prohibiciones en 1719, se admitió a Eugenia Caballero mujer de Diego de Acuña, como un pedido realizado por el conde de la Mejorada, Veinte y Cuatro, procurador mayor del cabildo y regimiento de Sevilla por haber hecho notables instancias a favor del hospital, en las epidemias como en todas las demás urgencias y "en lo mucho que en adelante sus buenos oficios puede favorecer hacia esta casa". Se recibió a la mujer sólo "por ser del agrado del Sr. Conde" ${ }^{60}$

En el inventario de 1726 ya no figura la sala de incurables, aunque se enviaban aún a ella a las madres que dejaban de trabajar en convalecencia por estar muy enfermas o viejas, lo más probable es que algunas camas de la sección de convalecientes fuesen para incurables y otras estuviesen dispersas en las diferentes enfermerías.

A pesar de todos los intentos por evitar la entrada de incurables, la realidad se impuso y continúo su fluida presencia desde mediados del siglo XVIII: En 1739, le dieron una cama de incurables a Catalina Sánchez, madre cirujana y salario de 14 reales cada mes para vestido y demás menesteres. ${ }^{61}$ En 1741, fue recibida Paula de Cabezuela a una cama de incurables, vecina de Sevilla por ser pobre, vieja y desvalida. ${ }^{2}$ En 1743 , se admitió a cama de incurables a Josepha Larios, doncella huérfana y enferma habitual sin poder servir. ${ }^{63}$ En ese año, se ordenó también liquidación de camas de incurables. En 1744, se nombró a una cama de incurables a Bernarda García, por ser pobre de solemnidad y sufrir achaques. En 1745, se nombró a una cama de incurables a Francisca García, 70 años, desamparada. En 1746 se nombraron a cuatro mujeres en camas de incurables, una viuda, una doncella, otra de 80 años y a una mujer que pagó 3 reales de vellón por día por ocupar una cama de enfermería hasta que ocupase la cama de incurables. En 1747 se nombró a una pobre de solemnidad a camas de incurables y en 1749 se nombraron a dos, una de ellas criada de un administrador del hospital. De esta manera, se formó una larga lista de espera para acceder a las camas de incurables, al grado que se podían quedar las enfermas en enfermería del hospital hasta acceder a una plaza de incurable.

59 ADPS. Legajo 4B. Autos capitulares de este Hospital de la Sangre de 1716 a 1734, f.18 r (1717).

60 ADPS. Ibidem, f.32 r (1719).

61 ADPS. Legajo 4B. Libro de autos capitulares pertenecientes al gobierno de este Hospital de la Sangre de 1734 a1763, f. 33 r (1739).

62 ADPS. Ibidem, f.45 r (1741).

63 ADPS. Ibidem, f.59 r (1743). 
En 1750 se suspendió el nombramiento a camas de incurables hasta que no se hiciera liquidación de su dotación. Una vez claras las cuentas, nombraron para una cama a María Chamorro, vecina de la ciudad de Sevilla, de 70 años, pobre de solemnidad. El otorgamiento de la cama la daba el patrono presidente del año. A partir de la segunda mitad del siglo XVIII, el acceso a una cama de incurables se hizo más monetario. En 1771, a solicitud de pretensión de una cama de incurables o de supernumeraria de Rosalía Fernández a cambio de una casa, le concedieron una cama de incurables supernumeraria, cuando vacase alguna. ${ }^{64}$ Mientras que a Nicolasa Bravo no le consintieron porque ofreció dar sólo 100 pesos a razón de 4 cada mes hasta cumplir con la cantidad propuesta. En 1773, las enfermas incurables solicitaron ser enterradas en la iglesia si es que no morían en el hospital, lo que fue denegado. Ya que sólo se enterraban en el hospital las que morían en ella. El área de incurables recuperó su sala porque la cama de incurables cobró, cada vez, más importancia a finales del siglo XVIII, al grado que había una larga lista de supernumerarias, en espera de que se desocuparan las camas, al morir alguna de sus ocupantes. Se colocaron hornillos de carbón, quitándolas de enfermería, privilegiando esta área desde $1775 .{ }^{65}$ Se convirtió en uno de los mejores ingresos económicos del hospital de esta época de crisis económica:

- En 1775, se nombró a una cama de incurable como supernumeraria a María Suárez Brito, la que dio una limosna de tres mil reales de vellón.

- En 1780, se nombró a Francisca Casa Galindo a una cama de incurables, entregaba cien ducados para su manutención anual, cantidad dada por Francisco Ordóñez del comercio de Sevilla. ${ }^{66}$

- En 1783, se nombró a Andrea Domínguez a una cama de incurables, quien entregaba cien ducados anuales.

- Ese mismo año, a Francisca Martínez se le recibió en cama de incurables y se le adjudicó la plaza de madre de incurables, dando a cambio la concesión de una casa. ${ }^{67}$

En 1791, los patronos del hospital determinaron que las siete camas de incurables, sólo, podían ser ocupadas por alguna de las impedidas que pertenecieran a la familia del hospital o enfermerías. Sólo podían acceder a incurables las que propusiesen el médico o el cirujano a través de los informes

64 ADPS. Legajo 4B. Libro de Auto Capitulares del Hospital de la Sangre, comienzo del año de 1764 a 1787, f.39 r (1770).

65 ADPS. Ibidem, f. 66 r (1775).

66 ADPS. Ibidem, f.115 r (1781).Ramos Carrillo, Antonio. Op. cit., p. 32. En 1780, las camas de incurables aumentaron en ocho.

67 ADPS. Legajo 4B. Libro de Auto Capitulares del Hospital de la Sangre, comienzo del año de 1764 a 1787, f.125 r (1783). 
que entregaban al señor administrador para los patronos del hospital. ${ }^{68}$ En 1794 , se asignó a la sala de incurables a Ana Cabrejos, hermana del mayordomo del hospital, a condición que éste diese cama y ropa suficiente y pagara 100 ducados anuales para la alimentación. ${ }^{69}$ En 1798 a la madre María Liñan se le adjudicó la primera cama de convaleciente que vacase, sin perjuicio de otra de la casa de mayor mérito. ${ }^{70}$

No todas las camas de incurables se compraban, muy de vez en cuando se entregaban a modo de limosna a una pobre necesitada. Así, se solicitaban una cama para algunas mujeres pobres avaladas por los curas del hospital. Tenemos el caso de Gertrudis Rodríguez, natural de Sevilla, vecina de la parroquia el San Lorenzo, frente de la calle y plazuela de los Tiros en la casa no 15 . Estaba casi ciega, huérfana de padre y madre. Era tan pobre que mendigaba por la ciudad, había sido atropellada varias veces por los coches y caballerías. No se podía asegurar el alimento diario. Se solicitaba por ella una vacante y nombramiento en la sala de incurables. Se pedía la certificación de ser pobre de solemnidad por el cura de la parroquia a la que pertenecía. Avalaron por ella, los curas del Hospital de la Sangre Juan Nepuceno y Meléndez Valdez. Solicitado en 1796 . $^{71}$

No se recibieron más incurables por 27 años, que coincidió con un periodo de convulsiones políticas y militares en Sevilla. ${ }^{72}$ Recién, en 1825 , se admitió la solicitud de Josefa Velásquez para una cama de incurables por hallarse enferma crónica de edad de 85 años. También, lo solicitó Francisca Zarate, pariente de la fundadora del hospital que cobró una dote que impuso la fundadora. La madre Sor María del Rosario del Espíritu Santo Bermúdez solicitó una cama de incurables para su madre Da. María Antonia González Hidalgo achacosa y en desamparo. A todas se las admitió cuando hubiese vacante. ${ }^{73}$ Sólo se concedió una cama de incurable a Josefa Benítez, la madre mayor, separada de su cargo por tener quebranta la salud. Esta mujer tenía 44 años de robusta salud, asumió el mando

68 ADPS. Legajo 4C. Libro de Auto Capitulares del Hospital de la Sangre de 1788 a 1800, f. $26 \mathrm{r}$-v (1791)."Que de aquí en adelante las pobres que hayan de entrar a ocupar las siete camas de incurables establecidas en este dicho hospital, habían de ser precisamente de alguna de las que impedidas se hallasen en las de familia, o enfermerías de él, y se propusieren a dichos Reverendos Señores Patronos, por el médico, o cirujano; los que por medio del Sr. Administrador deberán hacer sus informes en cada cama que vacare".

69 ADPS. Ibídem, f.62 r (1794).

70 ADPS. Ibidem, f.94 v (1798).

71 ADPS. Legajo 186. Tributos y aniversarios 1796. Papeles sueltos.

72 Ramos Carillo, Antonio, Op. cit., p. 35-38.En 1798 Carlos IV empieza una serie de expropiaciones a de los centros asistenciales y benéficos, poniendo fin a la independencia de estos centros. El año de 1808 marcó el inicio de serias convulsiones políticas, económicas y sociales, como la invasión francesa, la Guerra de la Independencia, la perdida de gran parte de sus dominios en América y la terrible depresión económica.

73 ADPS. Legajo 4C. Libro de Juntas y acuerdos capitulares que da principio en este presente ańo de 1800 a 1831 , f.138 v, f. 139 r y f.141 v (1825). 
del área femenina del hospital en mayo de 1830, sin embargo, en diciembre de 1831 se la separó del cargo porque no se "podía conseguir que dicha señora se corrigiese en algunos defectos que se lo han notado". Sin embargo, en notificación de despido se indicó que fue a causa de "estar quebrantada su salud", asistiéndola con una cama de incurables. ${ }^{74}$ Este acontecimiento no quiere decir que el exceso de trabajo de la madre mayor, impidió a esta mujer cumplirlo y menos en una época que habían descendido el número de enfermas, sino que podría ser una estrategia para obtener una cama de incurables, las más apetecibles del hospital, por las mujeres desahuciadas

En 1835, el Gobierno civil y la Junta de Beneficencia pidieron al visitador del Hospital de las Cinco Llagas un informe del número de incurables existentes en el hospital, expresando sus nombres, edades, fecha de ingreso y en virtud a que causa ocupaban las camas. Según Collantes de Terán Caamaño, en 1839 el número de camas de incurables se fijó en doce. ${ }^{75}$

74 ADPS. Ibidem, f.164 r-v (1831).

75 Collantes de Terán Caamaño, Francisco de Paula. Memorias históricas de los establecimientos de Caridad de Sevilla y descripción artística de los mismos(1884). Sevilla: Colegio Oficial de Aparejadores y Arquitectos Técnicos de Sevilla, 1980, p.151. Bernardo Escobar Perez. "El Hospital de las Cinco Llagas. Aproximacion histórica", en Arqueologia y rehabilitación en el Parlamento de Andalucía: investigaciones arqueológicas en el Antiguo Hospital de las Cinco Llagas de Sevilla. Sevilla : Parlamento de Andalucía, Servicio de Diario de Sesiones y Publicaciones no Periódicas, 2003, p.331. En 1627, el administrador del hospital Joffre de Loayssa pide licencia al ayuntamiento para cruzar con una cañería el arroyo Tagarete y hacer una zanja en el camino de Miraflores, para meter la tubería. El ayuntamiento accedió y se comenzaron a hacer los trabajos de canalización, construyéndose nuevas fuentes en los patrios del hospital. 


\begin{tabular}{|c|c|c|}
\hline \multicolumn{3}{|c|}{ Tabla 3.La sala de incurables de mujeres } \\
\hline 1620 & 1699 & 1725 \\
\hline $\begin{array}{l}20 \text { camas de a dos } \\
\text { colchones con dos } \\
\text { sábanas de amaino, dos } \\
\text { almohadas de crea, un } \\
\text { cobertor y una frazada } \\
\text { para cada cama. }\end{array}$ & \multirow{3}{*}{$\begin{array}{l}1 \text { altar portátil de madera con } \\
\text { un portal viejo de rasillo } \\
\text { Manteles con puntas antiguas. } \\
\text { Por retablo: un cuadro antiguo } \\
\text { del nacimiento y otro de } \\
\text { Nuestro Seńor con la cruz a } \\
\text { cuestas. } \\
\text { Se compró para el altar el día } \\
23 \text { de septiembre de1699, un } \\
\text { cuadro de nuestra Señora del } \\
\text { Rosario con Sta. Catalina y Sta. } \\
\text { Rosa. Esta enmarcado y tiene } \\
\text { dos varas. }\end{array}$} & \multirow{3}{*}{$\begin{array}{l}\text { Igual } \\
\text { El Señor con la Cruz a } \\
\text { cuestas esta en la sala de } \\
\text { convalecencia baja. } \\
\text { El cuadro de nuestra } \\
\text { Señora del Rosario con Sta. } \\
\text { Catalina y Sta. Rosa que } \\
\text { esta enmarcado y tiene dos } \\
\text { varas fue trasladado a la } \\
\text { sala de convalecencia baja. }\end{array}$} \\
\hline 1685 & & \\
\hline $\begin{array}{l}1 \text { altar portátil de madera } \\
\text { con su frontal muy } \\
\text { viejo de tafetán y fleco } \\
\text { de plata, manteles con } \\
\text { puntos antiguos y por } \\
\text { retablo un cuadro muy } \\
\text { antiguo del nacimiento y } \\
\text { otro del Jesús con la cruz } \\
\text { a cuestas. }\end{array}$ & & \\
\hline $\begin{array}{l}2 \text { esteras en las dos } \\
\text { puertas. }\end{array}$ & $\begin{array}{l}2 \text { esteras en las dos puertas de la } \\
\text { sala alta, ambas de esparto. }\end{array}$ & igual \\
\hline 12 tarimas. & 12 tarimas de pino. & igual \\
\hline 14 colchones. & 14 colchones. & igual \\
\hline 14 sábanas. & 14 sábanas. & igual \\
\hline 14 almohadas. & 14 almohadas. & igual \\
\hline 7 cobertores y 6 paños. & 7 cobertores y 6 paños. & igual \\
\hline $\begin{array}{l}1 \text { candil de metal con } 4 \\
\text { mecheros. }\end{array}$ & $\begin{array}{l}1 \text { velón de metal con su bola } \\
\text { hueca de lo mismo como los de } \\
\text { las enfermerías. }\end{array}$ & igual \\
\hline 5 banquillos. & 5 banquillos de entre camas. & igual \\
\hline $\begin{array}{l}1 \text { tarjeta donde está } \\
\text { tomada la razón de la } \\
\text { dotación de las camas } \\
\text { con el marco dorado. }\end{array}$ & 1 tarjeta con su marco dorado. & igual \\
\hline $\begin{array}{l}1 \text { copa de cobre con pies } \\
\text { de hierro. }\end{array}$ & $\begin{array}{l}1 \text { copa de cobre con pies de } \\
\text { hierro. }\end{array}$ & igual \\
\hline
\end{tabular}




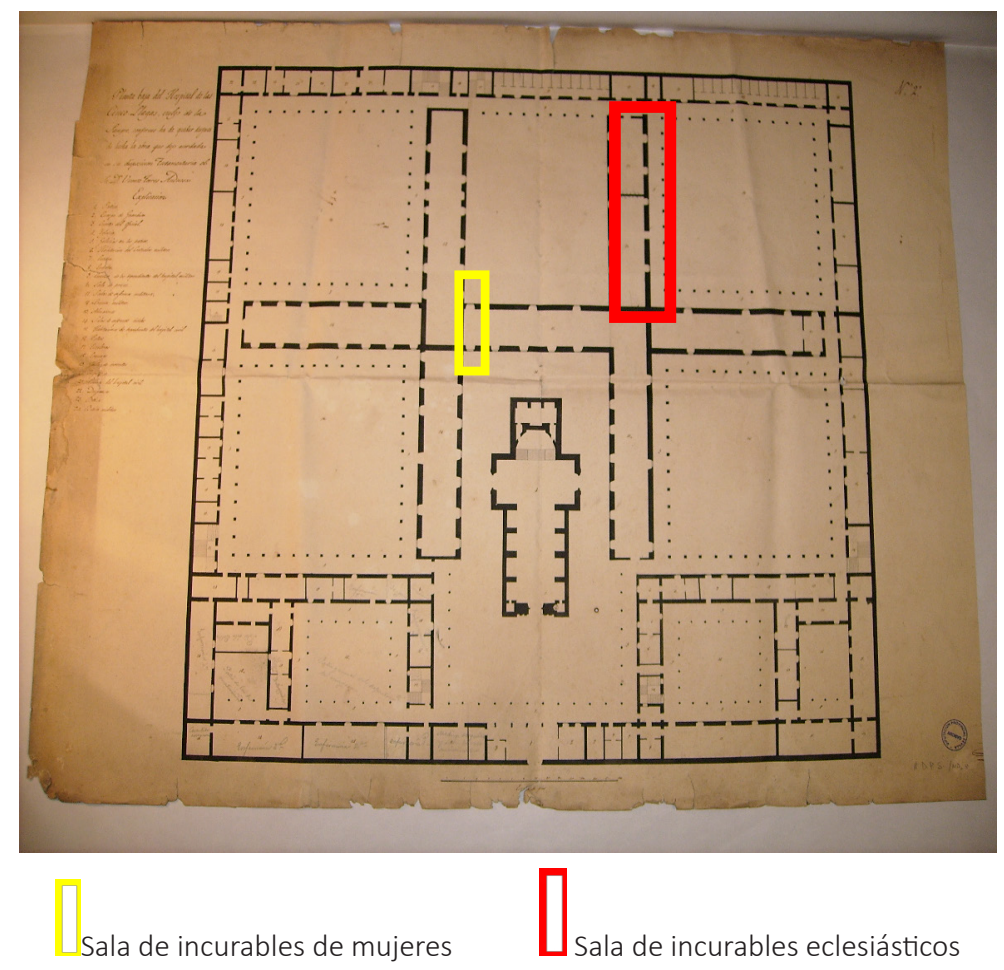

Fuente: A.D.S.P. / M.P. 8

Figura 1. La ubicación de la sala de incurables 